\title{
Maternal adiposity in pregnancy and offspring asthma in adulthood
}

\author{
To the Editor:
}

Adverse pre- and neonatal conditions, such as low birth weight and parental smoking, have, in recent years, been found to increase the risk of developing asthma $[1,2]$. The underlying mechanisms behind this appear to include an altered epigenetic programming of the developing fetal airways and immune system $[3,4]$.

One of these prenatal risk factors is maternal adiposity. Obesity in pregnant women is increasing and it has, in several cohort studies, been found to be associated with offspring asthma in childhood and in adolescence $[5,6]$. However, there are, to our knowledge, no previous studies focusing upon the association between maternal body mass index (BMI) and offspring asthma in later life. The aetiologies of asthma in adulthood differ from those of childhood asthma. Childhood asthma has a higher percentage of the allergic phenotype, while late-onset asthma in adulthood is associated with a more rapid decline in lung function $[7,8]$. Therefore, the impact of maternal BMI on asthma might differ in paediatric and adult cohorts. In this particular study, we examined the association between maternal adiposity and offspring asthma in adulthood.

The study included 12027 subjects who were part of the Helsinki Birth Cohort Study (HBCS), a cohort of 13345 men and women born in Helsinki during 1934-1944. Information about the subjects and their mothers was collected from hospital birth records, child welfare records and school health records. These data include weight and length at birth, gestational age, maternal weight and height prior to delivery, maternal age at birth, and parity. The subjects were divided into tertiles according to maternal BMI. The mean maternal BMI was $23.4 \mathrm{~kg} \cdot \mathrm{m}^{-2}$ in the lowest tertile, $25.9 \mathrm{~kg} \cdot \mathrm{m}^{-2}$ in the middle group and $29.3 \mathrm{~kg} \cdot \mathrm{m}^{-2}$ in the highest tertile. Subjects' occupations were acquired from Statistics Finland.

The prevalence of asthma was $7.1 \%$ for both sexes combined; $8.7 \%$ for women and $5.7 \%$ for men. The occurrence of asthma was defined as receiving special reimbursement for asthma medication. The costs of asthma medication are partly reimbursed by the state in Finland. In order to acquire special reimbursement, certain criteria must be filled and in adults, the criteria require demonstration of reversible airflow obstruction. The criteria for special reimbursement for asthma medication are further described in detail by BARKER et al. [1].

We used Cox proportional hazard models as the primary analytical tool to examine the associations between maternal adiposity and occurrence of asthma. The participants were followed up from the year 1964 to their death, migration, onset of asthma or December 31, 2011.

In the whole cohort, maternal BMI was significantly related to a higher occurrence of asthma. Compared to those whose mothers were in the lowest BMI tertile, those whose mothers were in the highest tertile had a higher hazard of asthma, the hazard ratio (HR) being 1.21 (95\% CI 1.03-1.43). In the analysis for men alone, the association was even stronger; HR was 1.44 (95\% CI 1.12-1.86). Maternal BMI was not associated with asthma among women. Additional adjustment for gestational age, parity, birth weight and socioeconomic status in adulthood further strengthened the associations (figure 1). With both sexes combined, the adjusted HR for asthma was 1.27 (95\% CI 1.07-1.52) in the highest maternal BMI group compared to the lowest group. For men, this HR was 1.54 (95\% CI 1.18-2.02).

We also performed these analyses in a subsample $(n=6874)$ with data on smoking history and adult BMI available. There was no significant association between maternal BMI and offspring asthma before adjustment for subjects' own BMI or smoking status, although the trend was similar to the analyses

@ERSpublications

High maternal body mass index in pregnancy is associated with an increased prevalence of offspring asthma in men in adult life http://ow.ly/cOWh30kWpBU

Cite this article as: Westberg AP, Salonen MK, von Bonsdorff M, et al. Maternal adiposity in pregnancy and offspring asthma in adulthood. Eur Respir J 2018; 52: 1801152 [https://doi.org/10.1183/ 13993003.01152-2018]. 

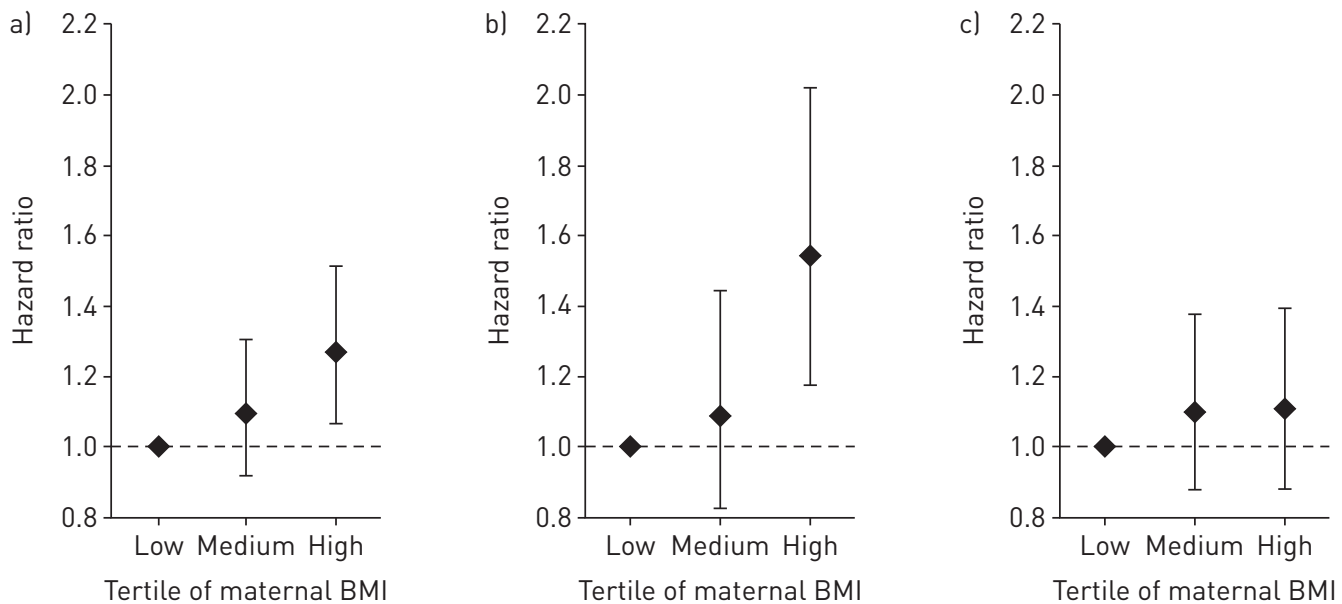

FIGURE 1 Hazard ratios and 95\% confidence intervals for special reimbursement for asthma medication according to tertiles of maternal body mass index (BMI). Stratified for date of birth, and adjusted for sex when both sexes are combined, and for gestational age, parity, birth weight and socioeconomic status in adulthood. a) Men and women; b) men; c) women.

performed with all subjects. Additionally, the results did not change when adding smoking status and adult BMI as covariates.

With data from HBCS, we have examined the effect of maternal BMI in late pregnancy on the occurrence of asthma in adult life in the offspring. While there are studies that have previously shown an association between high maternal BMI and offspring asthma in childhood and adolescence, this is, to our knowledge, the first study that demonstrated this association in late adult life particularly among men.

The mechanisms underlying the association between maternal BMI and offspring are likely to include common genetic factors and environmental conditions as well as epigenetic remodelling during fetal development. It is proposed that high maternal BMI during pregnancy causes an unfavourable hormonal and metabolic environment for the fetus [9]. This in turn may result in epigenetic programming, which adversely alters the development of the fetal immune system and results in a hyperresponsive airway epithelium, a characteristic of asthma [10]. Further research is required to fully understand the pathways by which maternal adiposity influences offspring asthma.

In this study, we found high maternal BMI to be associated with asthma in male, but not in female, subjects. We are not able to draw any definite conclusions on why there is a sex difference. However, fetal airway development differs in male and female fetuses, which hypothetically might expose the sexes differently to adverse neonatal conditions [11]. Sex differences have also been described in several other studies on neonatal conditions and later health outcome, supporting the theory that male and female fetuses are targets for different epigenetic remodelling [12, 13].

The study has some limitations. As the medications for asthma and chronic obstructive lung disease partly overlap, some of the subjects who received special reimbursement for asthma medication may in fact have suffered from chronic obstructive lung disease instead of or in combination with asthma. This method might also have excluded some mild cases of asthma, since the criteria for receiving the reimbursement include using medication regularly. Maternal BMI was calculated by using maternal weight prior to delivery and we were unable to distinguish between the impact of maternal pre-pregnancy weight and maternal weight gain during pregnancy on offspring asthma. Nevertheless, high maternal BMI before pregnancy and excessive gestational weight gain seem to have the same adverse effect on pregnancy and neonatal outcomes [14]. Another challenge regarding maternal BMI is that the mothers in the cohort were not as obese as pregnant women today.

The strengths of this study include a long follow-up period from birth until a mean age of 71 years, as well as reliable information on maternal and neonatal characteristics from hospital birth records. We also possessed information about the date of asthma diagnosis, which enabled us to perform the analyses with Cox regression. Finally, the prevalence of asthma in the cohort was $7.1 \%$, which corresponds well to the general prevalence in the Finnish population [15].

In conclusion, this study suggests that maternal BMI in late pregnancy is associated with an increased occurrence of asthma in male adult offspring after adjustment for year of birth, gestational age, parity, birth weight and socioeconomic status in adulthood. The study gives us further insight into how pre- and 
neonatal conditions adversely affect the risk of asthma in later life. Further insight into the risk factors for developing asthma might improve the possibilities for targeting primary prevention of the disease. Anna P. Westberg ${ }^{1,2}$, Minna K. Salonen
Johan G. Eriksson
, $^{2,3}$

${ }^{1}$ Dept of General Practice and Primary Health Care, University of Helsinki and Helsinki University Hospital, Helsinki, Finland. ${ }^{2}$ Folkhälsan Research Center, Helsinki, Finland. ${ }^{3}$ Chronic Disease Prevention Unit, National Institute for Health and Welfare, Helsinki, Finland. ${ }^{4}$ Gerontology Research Center, Faculty of Sport and Health Sciences, University of Jyväskylä, Jyväskylä, Finland. ${ }^{5}$ MRC Lifecourse Epidemiology Unit, University of Southampton, Southampton, UK. ${ }^{6}$ Children's Hospital, Helsinki University Hospital and University of Helsinki, Helsinki, Finland. ${ }^{7}$ PEDEGO Research Unit, MRC Oulu, Oulu University Hospital and University of Oulu, Oulu, Finland.

Correspondence: Anna P. Westberg, Dept of General Practice and Primary Health Care, University of Helsinki, PO Box 20, 00014 University of Helsinki, Helsinki, Finland. E-mail: anna.westberg@helsinki.fi

Received: June 032018 | Accepted after revision: July 102018

Conflict of interest: E. Kajantie reports receiving grants from the Academy of Finland, the European Commission, the Juho Vainio Foundation, the Signe and Ane Gyllenberg Foundation, and the Foundation for Pediatric Research, during the conduct of the study; and grants from the Sigrid Juselius Foundation, the Finnish Foundation for Cardiovascular Research, the Novo Nordisk Foundation and the Finnish Diabetes Research Foundation, outside the submitted work.

Support statement: This study was supported by Emil Aaltosen Säätiö, EU H2020-PHC-2014-DynaHealth (grant 633595), the European Commission 7th Framework Programme (Developmental Origins of Healthy and Unhealthy Ageing) (grant 278603), the Finnish Foundation for Diabetes Research, the Finnish Foundation for Pediatric Research, Finska Läkaresällskapet, the Juha Vainio Foundation, Medicinska Understödsföreningen Liv och Hälsa, the Novo Nordisk Foundation, Samfundet Folkhälsan, Signe ja Ane Gyllenbergin Säätiö, Sydäntutkimussäätiö and the Academy of Finland (grants 127437, 129306, 130326, 134791, 263924 and 274794 to E. Kajante, 129369, 129907, 135072, 129255 and 126775 to J.G. Eriksson, and 257239 to M. von Bondsdorff). Funding information for this article has been deposited with the Crossref Funder Registry.

\section{References}

1 Barker DJ, Osmond C, Forsen TJ, et al. Foetal and childhood growth and asthma in adult life. Acta Paediatr 2013; 102: 732-738.

2 Burke H, Leonardi-Bee J, Hashim A, et al. Prenatal and passive smoke exposure and incidence of asthma and wheeze: systematic review and meta-analysis. Pediatrics 2012; 129: 735-744.

3 Martino D, Prescott S. Epigenetics and prenatal influences on asthma and allergic airways disease. Chest 2011; 139: 640-647.

4 Peters JL, Boynton-Jarrett R, Sandel M. Prenatal environmental factors influencing IgE levels, atopy and early asthma. Curr Opin Allergy Clin Immunol 2013; 13: 187-192.

5 Fisher SC, Kim SY, Sharma AJ, et al. Is obesity still increasing among pregnant women? Prepregnancy obesity trends in 20 states, 2003-2009. Prev Med 2013; 56: 372-378.

6 Zugna D, Galassi C, Annesi-Maesano I, et al. Maternal complications in pregnancy and wheezing in early childhood: a pooled analysis of 14 birth cohorts. Int J Epidemiol 2015; 44: 199-208.

7 Bel EH. Clinical phenotypes of asthma. Curr Opin Pulm Med 2004; 10: 44-50.

8 Miranda C, Busacker A, Balzar S, et al. Distinguishing severe asthma phenotypes: role of age at onset and eosinophilic inflammation. J Allergy Clin Immunol 2004; 113: 101-108.

9 Ramsay JE, Ferrell WR, Crawford L, et al. Maternal obesity is associated with dysregulation of metabolic, vascular, and inflammatory pathways. J Clin Endocrinol Metab 2002; 87: 4231-4237.

10 MacDonald KD, Moran AR, Scherman AJ, et al. Maternal high-fat diet in mice leads to innate airway hyperresponsiveness in the adult offspring. Physiol Rep 2017; 5: https://doi.org/10.14814/phy2.13082.

11 Becklake MR, Kauffmann F. Gender differences in airway behaviour over the human life span. Thorax 1999; 54: 1119-1138.

12 Barker DJ, Osmond C, Kajantie E, et al. Growth and chronic disease: findings in the Helsinki Birth Cohort. Ann Hum Biol 2009; 36: 445-458.

13 Dumas O, Varraso R, Gillman MW, et al. Longitudinal study of maternal body mass index, gestational weight gain, and offspring asthma. Allergy 2016; 71: 1295-1304.

14 Li N, Liu E, Guo J, et al. Maternal prepregnancy body mass index and gestational weight gain on pregnancy outcomes. PLoS One 2013; 8: e82310.

15 Jousilahti P, Laatikainen T, Haahtela $\mathrm{T}$, et al. Astma ja hengitystieallergiat ovat lisääntyneet Suomessa allergiaohjelma pyrkii taittamaan kasvun. Tutkimuksesta Tiiviisti 2016; 5. 